\title{
A RELAÇÃO DIALÉTICA ENTRE SINDICATOS, CONSCIÊNCIA DE CLASSE E ORGANIZAÇÃO POLÍTICA DOS TRABALHADORES
}

\author{
THE DIALECTICAL RELATIONSHIP BETWEEN UNIONS, CLASS \\ CONSCIOUSNESS AND POLITICAL ORGANIZATION OF WORKERS
}

\author{
Helder Molina*
}

\section{RESUMO}

Estas notas problematizam a contraditória e complexa relação dialética entre sindicatos, partidos, organização e consciência de classe. Coerente com 0 materialismo histórico e dialético, discutirmos que a ruptura estrutural de um modo de produção, não é meramente um evento político, mas um processo social, um movimento prático de transformação, através do qual os trabalhadores adquirem uma percepção de sua existência social, enquanto, ao mesmo tempo, nega e destrói o sistema de dominação.Isto não significa subestimar o papel desempenhado pela teoria mas, preferencialmente, significa coloca-la no devido lugar, A consciência de classe é, portanto, uma síntese, tirada da experiência pessoal adquirida no decorrer de uma prolongada luta, que criticamente revê todo o conhecimento previamente disponível. É indispensável, ao mesmo tempo, que os trabalhadores compreendem a essência da sociedade capitalista, as relações de exploração entres as classes sociais, e suas próprias tarefas históricas ${ }^{13}$

Palavras-chave: Trabalho - Sindicalismo - Consciência de Classe Organização Política.

\section{ABSTRACT:}

These notes question the contradictory and complex dialectical relationship between unions, parties, organization and class consciousness. Consistent with the historical and dialectical materialism, we discuss the structural breakdown of a mode of production, is not merely a political event but a social process, a practical movement of transformation, through which workers acquire a perception of their social existence, while at the same time, deny and destroy the system of domination. This is not to underestimate the role played by theory but, rather, it means put in place, Class consciousness is therefore a synthesis drawn from personal experience gained during a prolonged fight that critically

${ }^{1}$ Mao Tse Tung. Sobre a Prática, in Obras Escolhidas, Global, 1988, vol. I, p.323 
reviewing all knowledge previously available. It is essential at the same time, that they understand the essence of capitalist society, the relations of exploitation entres social classes, and their own historical tasks

Keywords: Labor Unionism - Class Consciousness - Political Organization

\section{INTRODUÇÃO}

\section{TEORIA, PRÁXIS E FORMAÇÃO DA CONSCIÊNCIA DE CLASSE}

A emancipação dos trabalhadores deve ser obra pelos próprios trabalhadores. Esta afirmação inicial nos estatutos da $1^{\text {a }}$ Internacional foi escrita por Marx, em 1864. Como Engels ressaltou alguns anos depois, a declaração sintetiza a sua "confiança total no desenvolvimento intelectual da classe operária" Foi esta confiança que os levou a ambos além do manifesto comunista, e se constitui em uma de suas mais originais contribuições ao movimento operário.

De acordo com Marx, os trabalhadores não podem ser educados por uma fonte externa, dada a unidade indivisível entre teoria e prática, a consciência só pode se desenvolver através da práxis (sua própria, e não a de outro alguém) luta, ação e experiência.

A teoria contribui para a construção da consciência de classe, pois oferece uma estrutura que mostra o processo de formação e desenvolvimento da consciência. A teoria marxista, como uma guia de ação para o movimento operário, não pode ser trazida para a luta de classes de fora para dentro, mas, ao contrário, deriva de experiências concretas dos trabalhadores, e reflete-se sobre a experiência para fazer avanças suas próprias lutas.

Assim, então, como este processo pode ser elucidado? Onde pode ser encontrada a forma predominante de consciência de classe? Em cada conjuntura, esta forma de consciência revela a distância entre os dois aspectos da natureza da classe trabalhadora, ou mais precisamente, a contradição entre sua essência e sua existência?

A terceira tese sobre Feuerbach responde, em termos globais: $\mathrm{Na}$ práxis concreta da classe. Ma como uma ação empreendida por um sujeito real 
coletivo, esta práxis surge fragmentada porque a classe é, na realidade, heterogênea. Está fracionada em grupos mais ou menos contingentes, cujas ações são, por isso, desarticuladas.

A práxis parece complexa porque a classe trabalhadora atua em vários níveis e suas coes têm âmbitos e conteúdos diferentes; embora tente lançar um desafio integrado para esta desarticulação, que é constantemente incentivada pelos sistema como um elemento chave em sua estratégia de dominação.

Aqui, como o risco de retroceder à metafísica do sujeito, é importante estabelecer um ponto básico. Estas afirmações devem ser entendidas dialeticamente, dado que a classe trabalhadora não tem uma identidade histórica que preceda a práxis complexa, fragmentada e concreta .

Assim, a classe não é uma "coisa", uma categoria estatística que possa ser definida a priori e na qual a "consciência correta" possa ser abstratamente injetada de fora para dentro. A classe é um processo histórico situado num contexto particular. Possui suas próprias características nacionais e é limitada pela especificidade de lutas que emergem das tradições, sistemas de valores, idéias e modos concretos de organizações, e deles se tornam parte.

A consciência de classe, e o projeto emancipatório advindo desta, não é uma determinação histórica, e não está na natureza do processo histórico, ao contrário, tarefa cuja realidade emerge de sua correspondência a uma tendência objetiva de desenvolvimento histórico; embora a maturação de condições concretas possa tornar essa tarefa possível, não a torna necessariamente inevitável.

Quando muito, em princípios bem dialéticos, aquelas condições não podem amadurecer integralmente, sem que a classe trabalhadora desenvolva sua conciência, de maneira a transformar tais condições em meios para sua própria emancipação.

Uma investigação das formas predominantes de consciência de classe pressupõe uma análise histórica de uma multiplicidade de práticas institucionalizadas e não institucionalizadas. Estas práticas não podem ser sintetizadas de forma simplista não só porque essa forma é em si 
multidimensional, mas também porque de fatos as dimensões são sempre assimetricamente desenvolvidas.Apesar da extrema dificuldade desta tarefa, ela permanece, não obstante, como pronto de partida necessária para a intervenção política que esteja por se efetivas.

\section{CONSCIÊNCIA DE CLASSE E A ORGANIZAÇÃO POLÍTICA DA CLASSE TRABALHADORA}

A consciência de classe, e a organização política da classe trabalhadora como sujeito coletivo, não pode ser tomada de forma hierarquizada, conforme a elaboram algumas concepções vanguardistas de partido e de sindicato.

Nessa hierarquização, na base estariam as massas trabalhadoras, e no ponto mais alto estará a direção do partido, e entre os dois haveria os sindicatos, operando como correias de transmissão e ligação da "política correta" com as massas.

O sindicato, nesta concepção, é visto como uma camada intermediaria, um aparelho instrumental, um elo de mediação, ou de implementação das políticas do partido para as massas. O partido pensa, o sindicato opera, as massas recebem. Esta imagem postula dois conceitos Um deles é o sugerido por níveis mais altos e mais baixos - hierarquia. O segundo é a homogeneidade. Esta imagem é particularmente conveniente às concepções vanguardistas.

Dado que a base é concebida como uma massa inerte, dominada pela ideologia burguesa e capaz de gerar somente demandas econômicas para os quais os sindicatos dão alguma forma coletiva, o partido, veículo através do qual a consciência externa penetra nas massas, controla, logicamente, a totalidade e está situado no ápice da pirâmide.

Esta é a razão porque se torna importante, para os sindicatos, que são organizações de massas, se submeterem ao ápice da pirâmide, desta forma agirem como correio de transmissão entre o partido e seus membros, concedendo uma dimensão política às lutas que, de outro modo, não a teriam. 
Historicamente, um vanguardismo invertido lança a hipótese de a revolução ser um ato fundamentalmente político, um freio repentino e violento, que requer uma concentração total de energias para o instante transitório, durante a qual a tomada de poder torna-se possível. O partido é, então EstadoMaior, incumbido de levar adiante o processo de ruptura.

Essa concepção de consciência e organização de classe em compartimentos hierárquicos alimenta a teoria de que a consciência é externa. Tendo o partido como uma vanguarda externa, com o objetivo de estimular a formação e o crescimento de quadros internos produzidos na luta de classes, advindos dela. Seria um equívoco toma-lo como direção apartada da classe, superior e fora do processo concreto desta. Para conquistar as massas, fazendo-as reconhecê-las como lideranças, queiram ou não.

A autonomia e variedade das experiências das lutas dos trabalhadores serão encorajadas a fazer no leito de seus processos coletivos. Numa concepção vanguardista, as massas são forçadas a seguir as palavras de ordem e as doutrinas produzidas por um grupo que se reivindica e se proclama superior a elas.

Assim, quanto mais atenção se der à formação e organização das massas, seja no processo de reflexão teórica, seja na ação prática, respeitando sua diversidade, seu estado de ânimo, estimulando sua unidade, mais possibilidade ela terá de reconhecer no sindicato e no partido aqueles sujeitos legitimados para dirigi-la.

Vemos-nos diante de uma concepção de ruptura essencialmente como evento político, que requer a existência de uma vanguarda, portadora de teoria, consciência, programa e linha revolucionária, e de uma outra, ou de outras, que concebem a ruptura com processo social, político e cultural, de complexas dimensões e diferenciadas durações.

O sujeito coletivo define sua identidade complexa através da mediação e articulação de práticas relativamente autônomas, que têm características particulares, e tendem a se desenvolver assimetricamente.

Duas importantes consequências surgem dessas observações. Uma é que a autonomia dos trabalhadores e a democracia de base não existirão somente como uma função da estrutura de cada nível (massa, sindicato, 
partido).Existirão também comum uma função de articulação, mediadora, entre níveis de dentro de uma complexa totalidade que eles próprios constituem e que defini a classe como um sujetro histórico.

A outra consequência destas observações mostra um desenvolvimento desigual daquelas forças sociais. Num certo momento, uma delas pode tender a ser dominante no processo de mobilização de massa, daí, então, indicando as tarefas principais que devem ser cumpridas nessa conjuntura particular.

Assim, por exemplo, durante o período de retração e passividade no movimento dos trabalhadores europeus, que se seguiu às tentativas revolucionárias de 1848 a 1870, Marx e Engels - contrariamente a Lassale atribuíram um papel central aos sindicatos, e não aos partidos.

\section{NOTAS SOBRE O PAPEL DOS SINDICATOS EM LÊNIN, ROSA LUXEMBURGO E GRAMSCI}

Do mesmo modo, em O Que Fazer? há uma base prática colocada para o papel do partido, que corroboram as posições teóricas acima. Lênin afirma que as massas não podem, espontaneamente, transcender a consciência economicista. E, ainda, é significante que, repetidamente, enfatiza a necessidade de se criar o partido, como unidade da teoria e da ação revolucionária entre as massas.

Sob estas condições, é a consciência espontânea que transcende a atividade consciente da organização social, e é subestimada pelas abordagens economicistas. Daí, Lênin viu a urgência de consolidar um núcleo revolucionário rela, que superaria os métodos de trabalho primitivos dos círculos socialistas, num país onde era necessário atuar clandestinamente, onde um partido nacional dos trabalhadores ainda não havia se formado e onde os poucos sindicatos existentes eram ilegais e maciçamente perseguidos. $^{2}$

\footnotetext{
${ }^{2}$ Lênin, O Que Fazer? p. 18, 427, 436, 442 etc, e especialmente na p.509. Falando das necessidade imediatas e práticas, que estamos analisando, e que foram posteriormente abandonados pelos militantes . Alguns anos depois, Lênin disse que o principal erro cometido por aqueles que fazem polêmicas contra $\mathrm{O}$ Que Fazer? é que eles separam totalmente este trabalho de seu contexto histórico específico, de um
} 
A perspectiva de Rosa Luxemburgo (1979) está baseada numa realidade social diferente, e abre uma terceira alternativa. Como militante do movimento social democrático alemão, ela atuou no centro da mais poderosa organização proletária, em sua época. Este caso sempre fascinou Lênin, que se referiu a ele frequentemente em seus escritos.

De acordo com Rosa Luxemburgo (1979), estas foram as forças sociais decisivas em uma situação que ela considerava revolucionária. Enquanto refletia, em 1906, sobre a experiência dos soviets russos um ano antes, e o papel da da base e da direção, afirmava que "não é a cúpula, no ápice das organizações e suas federações, mas, antes, é a base, nas massas proletárias organizadas, que se encontra a garantia da unidade real do movimento operária, e sua força política transformadora". ${ }^{3}$

Analisando de forma dialética, todas as críticas discutidas até agora, implicitamente desafiam qualquer conceito a priori, de hierarquia. Parece apropriado, contudo considera rapidamente dois problemas complexos e específicos que tende a ser subestimados neste campo. Estes dois problemas consistem na dicotomia estabelecida entre lutas sociais e políticas e no modo pelo qual a espontaneidade está vinculada à uma direção consciente.

A fase monopolista do capitalismo tornou-se a primeira distinção menos relevante. O potencial político, ideológico e econômico. Esse potencial também cresceu, até que os mecanismos principais de controle social passaram a ser subordinados a racionalidade do grande capital.

Isto se evidencia pelos esforços constantes em relação à despolitização dos conflitos que o sistema tem que levar a cabo, Se, por um lado a lógica do desenvolvimento capitalista penetra em todas as esferas da vida social, cada uma delas se torna, por outro lado, uma área possível de lutas políticas que podem lançar esta lógica numa crise. Hoje, mais do que nunca, a dinâmica social da revolução política toma a forma de um processo social.

Gramsci reconhece a vida nos movimentos de massas no terreno político. Também de grande importância a espontaneidade da classe operaria e

período concreto no desenvolvimento do partido, que agora pertence ao passado. (V.I Lênin. Obras Completas, Global, p.95)

${ }^{3}$ Rosa Luxemburgo. Greve de massas, Partido e Sindicato. Lisboa: Edições Avante, 1979, p. 123). 
à sua necessária unidade dialética com uma direção consciente. Tal visão fortalecer a crítica de qualquer concepção hierárquica.

Tal visão fortalece a critica de qualquer concepção hierárquica de organização que, na prática tolhe todos os níveis de luta, falhando no reconhecimento da especificidade de cada uma. Estritamente falando, não se pode falar de uma diferença de níveis, mas sim de tarefas. As função da vanguarda não é de injetar a dimensão política nas lutas sociais, mas participar, mediar e canalizar o desdobramento de seu próprio potencial político.

Cada conjuntura histórico-social traz uma forma equivalente de consciência de classe. Isso demonstra a complexidade da forma prevalente de consciência de classe. A legitimação das atividades sindicais e a institucionalização do conflito do trabalho contra o capital implicam, na prática, em dar prioridade às demandas econômicas que questiona o próprio modo capitalista de produção. Pela sua própria natureza, a organização sindical tem como base o espaço da produção, mas deve ter como intenção sair para fora dele, e agir para além do econômico-corporativo.

O sindicato se enquadra na lógica do sistema capital. Ao aceitar como seus membros somente aqueles que vendem sua força de trabalho em empresas e ramos produtivos aos quais estão ligados. Nesse sentido, sua função é receber as demandas de grupos específicos de vendedores de força de trabalho e negociar um preço (em forma de salário) para esta mão de obra. Como produto disso, o sindicato, pela sua própria natureza, leva o trabalhador a perceber o seu trabalho diário não como um processo de produção, mas simplesmente como um meio de ganhar dinheiro ${ }^{4}$.

Esta visão só poderia ser contestada somente pelos que menosprezam a especificidade deste nível de luta e pressupõem como papel central do sindicato a luta pela revolução, com um programa maximalista sem mediações com o estado de espírito, a relação de forças e estágio de consciência da classe.

Ao recusar, ou secundarizar o papel do sindicato como negociador da venda da força de trabalho, e a partir dela realizar um processo de

${ }^{4}$ Gramsci, Sindicalismo e conselhos de fábricas, obras completas, p. 428) 
mediação e educação política das massas, no sentido da superação dessa relação, as organizações sindicais abrem mão de uma possibilidade concreta de realizar junto com sua base a experimentação dos limites da luta meramente salarial, sem a qual não haveria um salto de consciência e tomada de posição para superação dessa relação.

Por outro lado, o sindicato atuando apenas no fenômeno salarial, prisioneiro das condições objetivas, e sem uma pressão política, organizada e coletiva, por parte dos trabalhadores, o sindicato tenderia a operar apenas ao nível dos efeitos, e não das causas da exploração capitalista. Utilizando uma linguagem marxista, atacaria os fenômenos, a aparência, e não a essência, a materialidade concreta.

Ao trocar melhores condições de trabalho e ruptura nos processos de produção e gestão, por recompensas monetárias, como bônus, benefício de saúde, cestas básicas, seguros contra acidentes de trabalho, pagamentos de horas extras, etc., submetida à lógica capitalista e aos limites impostos pelo capital.

\section{CONCLUSÃO}

O espaço da produção, ou o local de trabalho, por excelência, é o terreno onde se estabelecem e podem ser verificadas empiricamente as contradições da exploração e dominação do capital contra o trabalho. O lugar onde a luta se inicia porque é nele que se condensa o conflito entre 0 desenvolvimento do caráter coletivo do trabalho, e o controle privado de sua organização, e da apropriação do trabalho do trabalhador na forma de mais valia.

O espaço da produção, a fábrica, como classicamente a conhecemos, é concebida pelo sindicato como lugar primordial que possibilidade aos trabalhadores se perceberem como classe, partir do processo de aguçamento das contradições, como parte da totalidade social que deve ser transformada. O lócus da intervenção política, portanto, que deve ser potencializada pela ação organizada e consciente, ao mesmo tempo que é a unidade de produção em que a capacidade criativa dos trabalhadores 
encontra-se alienada. Onde a brutalidade da divisão capitalista do trabalho é mais concretamente revelada como uma subutilização programada da potencial energia intelectual dos trabalhadores.

A fábrica, ou o espaço da produção capitalista, é portanto, sua parte mais sensível. A natureza exploradora e repressiva manifesta-se diariamente, e numa tal dimensão que o esforço ideológico dirige-se menos para mascarar estar características que para difundir a imagem de sua inevitabilidade.

A ideologia dominante apresenta tais características como dados puramente técnicos, a fim de desviar a atenção dos trabalhadores para o consumo, para uma falsa satisfação fora do cativeiro do trabalho assalariado capitalista. Sob condições normais, há uma aceitação pragmática desta situação entre os trabalhadores, pela relativa fraqueza neste nível específico de relação de forças.

Os trabalhadores podem ser membros do sindicato, ou de um partido de classe, mas num caso, estarão unidos a partir da condição de vendedores de força de trabalho, dentro de uma unidade disciplinar com métodos de produção e sociabilização restrita e restritiva, porém, paradoxalmente, o lugar onde eles podem se descobrirem como classe. Unidos a partir da fábrica, $s$ descobrem fora dela, no sindicato, atuando organicamente como sujeito coletivo que de fato são.

\section{REFERÊNCIAS}

ALVES, Giovanni. O novo (e precário) mundo do trabalho. Reestruturação produtiva e crise do sindicalismo. São Paulo: Ed. Boitempo, 2000.

Giovanni. Reestruturação produtiva e crise do sindicalismo. São Paulo: Boitempo, 2005.

ANTUNES, Ricardo (org.). Neoliberalismo, trabalho e sindicatos: Reestruturação produtiva no Brasil e Inglaterra, $1^{\sharp}$ ed., Boitempo, SP, 1997.

BALADONI, Nicola. Filosofia da práxis. Gramsci e o Brasil. Disponível em: 
$<$ http://www.acessa.com/gramsci/> .

BOITO Jr., Armando. Política neoliberal e sindicalismo no Brasil. São Paulo: Xamã, 1999.

- Hegemonia neoliberal e sindicalismo no Brasil. Crítica Marxista, São Paulo, vol. 1, n. 3, p. 80-106, 1996.

GOETTERT. J. D., Cadernos CNTE - História do Sindicalismo. Brasília-DF: [s.n.], 2000.

GRAMSCI, Antonio. Sobre Democracia Operaria e outros textos. Lisboa: Ulmeiro, 1976. (Biblioteca Ulmeiro, n. 4).

A reconstrução do materialismo histórico. Madrid: Taurus, 1986.

. Concepção dialética da história. Rio de Janeiro: Civilização Brasileira, 1995.

. Cadernos do cárcere. Tradução de Carlos Nelson Coutinho com a colaboração de Luiz Sergio Henriques e Marco Aurélio Nogueira. Rio de Janeiro: Editora Civilização Brasileira, 1999.

HARVEY. David. Condição pós-moderna: uma pesquisa sobre as origens da mudança cultural. 12. ed. São Paulo: Ed. Loyola, 2003.

JAMESON, Fredric. A cultura do dinheiro: ensaios sobre a globalização. Tradução de Maria Elisa Cevasco e Marcos César de Paula Soares. 3. ed. Petrópolis: Vozes, 2001.

CATTANNI, A. D.; HOLZMANN, L. (Orgs.). Dicionário: trabalho e tecnologia. Porto Alegre: Editora da UFRGS, 1997. 
KOSIK, Karel. Dialética do concreto. São Paulo: Paz e Terra, 1976.

LÊNIN. V.I. Que fazer? Problemas candentes do nosso movimento. Edições Avante; 1986. 8a $a^{\mathrm{a}}$ Edição. Lisboa/Portugal: Ulmeiro. 1976.

LUXEMBURGO, Rosa. Greve de massas, partidos e sindicatos. Rio de Janeiro: Global, 1976.

LUKACS, G. As tarefas da filosofia marxista na nova democracia. Budapeste: [s.n.], 1948.

MARX e Engels. 18 Brumário de Napoleão Bonaparte. Rio de Janeiro: Civilização Brasileira, 1975.

A Ideologia Alemã. São Paulo: Hucitec, 1993.

Manuscritos de 1844, n.22, Obras Escolhidas. São Paulo: Alfa-Omega, 1986.

Contribuição à crítica da economia política. São Paulo: Martins Fontes, 1993.

MARX, Karl. Manuscritos econômico-filosóficos. Tradução de Jesus Ranieri. São Paulo: Boitempo, 2004.

O capital. Rio de Janeiro: Civilização Brasileira, 1975, vol. I.

. Manifesto do Partido Comunista. São Paulo: Ed. Global, 1990.

. O Capital. Rio de Janeiro: Civilização Brasileira, 1991, vol. I e II.

MAO TSE TUNG. Sobre a Prática. In: Obras Escolhidas. São Paulo: Ed. Global, 1988, vol. I. 
MOLINA, Helder. Metamorfose capitalista e educação dos trabalhadores: a travessia contraditória. (Uma análise da política de formação da CUT e do programa Integrar no Rio de Janeiro). 2004. 190 f. Dissertação (Mestrado em Educação) - Faculdade de Educação, Universidade Federal Fluminense, Niterói, 2004.

Breve História das Lutas e Concepções Políticas dos Trabalhadores no Brasil. Texto para Curso de Formação Sindical. Rio de Janeiro: Sindpd/RJ, 1999.

. Transição do Sistema Escravista para o Capitalismo Industrial no Brasil. Rio de Janeiro: Programa Integração-CUT, 2001.

THOMPSOM. E. P.A. Formação da Classe Operária Inglesa. Trad. Denise Bottmann (vols. I e III) e Renato Busatto Neto e Cláudia Rocha de Almeida (vol. II). São Paulo: Paz e Terra, 1987.

*

Professorheldermolina@gmail.com

Doutor em Políticas Públicas e Formação Humana (Programa de Pós Graduação em Políticas Públicas e Formação Humana - PPFH/UERJ); Mestre em Educação (Faculdade de Educação - NEDDATE-UFF); Licenciado e Bacharel em História (Faculdade de História - ICHF/UFF).

Professor da Faculdade de Educação da UERJ - Universidade do Estado do Rio de Janeiro, Assessor de Formação Política e Planejamento de Gestão, Pesquisador e Educador Sindical.

RECEBIDO EM: 07.12 .12

APROVADO EM: 27.12 .13 